\title{
XL Aniversario de la Fundación de la Federación \\ Panamericana e Ibérica de Medicina Crítica \\ y Terapia Intensiva (FEPIMCTI)
}

XL Anniversary of the Foundation of the Ibero Pan American Federation in Critical Medicine and Intensive Therapy (FEPIMCTI)

XL aniversário da Fundação da Federação Ibero Pan-Americana e Medicina Crítica e Terapia Intensiva (FEPIMCTI)

Durante el XLVI Congreso Anual del Colegio Mexicano de Medicina Crítica, realizado en la ciudad de León, Guanajuato, se llevó a cabo la ceremonia conmemorativa del XL Aniversario de la Fundación de la Federación Panamericana e Ibérica de Medicina Crítica y Terapia Intensiva (FEPIMCTI), en la que el Dr. Alfredo F. Sierra Unzueta dio un discurso muy emotivo sobre la historia de su fundación.

El presídium estaba integrado por el Dr. Jorge Rosendo Sánchez Medina (Presidente del COMMEC, México), el Dr. Néstor Raimondi (Presidente de la FEPIMCTI, Argentina), el Dr. Andrés Esteban (España), Dr. Alfredo Sierra (México), el Dr. Rolando Gimbernat (Secretario de la FEPIMCTI, Argentina), el Dr. Alfredo Matos (Tesorero de la FEPIMCTI, Panamá), el Dr. José Vergara (Consejero de la FEPIMCTI, Ecuador), el Dr. Agamenón Quintero (Consejero de la FEPIMCTI, Colombia), la Dra. María Cruz Martín (Consejera de la FEPIMCTI, España), el Dr. Ulises W. Cerón Díaz (Consejero de la FEPIMCTI, México) y la Dra. Gloria Rodríguez (Consejera la de FEPIMCTI, EUA).

A continuación, se transcriben las palabras del Dr. Alfredo Sierra:

Quiero darles algunas precisiones relacionadas con la historia de nuestra querida FEPIMCTI.

En el año de 1973, en la Ciudad de México, se fundó la Asociación Mexicana de Medicina Crítica y Terapia Intensiva (AMMCTI), hoy Colegio Mexicano de Medicina Crítica (COMMEC), en donde el primer presidente fue el Dr. Alberto Villazón Sahagún, al tiempo en que el Dr. Peter Safar era presidente de la Society of Critical Care. En ese mismo año, se celebró la primera reunión de carácter mundial sobre Terapia Intensiva en la ciudad de Londres, Inglaterra, bajo la Presidencia del Dr. Alan Gilston, un visionario y destacado anestesiólogo.

El siguiente Congreso Mundial tuvo lugar en la ciudad de París, Francia, en 1977. A este evento acudieron los delegados de la AMMCTI, encabezados por el Dr. Alberto Villazón, quienes asistieron para solicitar la sede del siguiente Congreso Mundial. En esa ocasión,

www.medigraphic.com/medicinacritica no se concedió a México esta distinción, pero sí se logró la posibilidad de organizar un evento panamericano para 1979 en nuestro país.

Desde su regreso de París, el Dr. Villazón y los intensivistas de la época nos dimos a la tarea de organizar este evento. Para ese entonces era necesario la fundación de una Federación Panamericana e Ibérica de Medicina Crítica y Terapia Intensiva, por lo que, para el mes de septiembre de 1979, se iniciaron los trámites para la fundación de la FEPIMCTI, eligiendo al Dr. Alberto Villazón como su primer presidente.

A continuación, se dan algunas notas que corresponden a la Asamblea Constitutiva de la FEPIMCTI:

1. El Acta de la Asamblea Constitutiva con fecha del 12 de septiembre de 1980 ante el notario público corresponde a la asamblea efectuada el 26 de septiembre de 1979 a las 19:00 horas en el Hotel Hilton de la Ciudad de México.

2. Los representantes de los siguientes países en orden alfabético fueron: Argentina, Bolivia, Brasil, Canadá, Colombia, España, Estados Unidos de Norte América, México, Perú, Portugal y Venezuela.

3. En dicha reunión, además, estuvieron como observadores y testigos los siguientes países: Chile, Ecuador, Panamá y Uruguay.

De tal forma que la Comisión Directiva de la Federación Panamericana e Ibérica de Medicina Crítica y Terapia Intensiva quedó constituida de la siguiente manera:

Presidente: Dr. Alberto Villazón Sahagún (México).

Secretarios: Dr. Sergio Rangel Carrillo (México), Dr. Héctor de Leone (Argentina), Dr. Julio Polisuk (Brasil), Dr. Eduardo García Vargas (Colombia), Dr. Roberto Arreaza (Venezuela).

Asimismo, en dicha Asamblea se nombró un Comité de Estatutos formado por los siguientes médicos y países que representan:

Comité de Estatutos: Dr. Mario Perman (Argentina), Dra. Maritza D’Agostino (Brasil), Dr. Andrés Esteban (España), Dr. Luis Hervella Pérez (México). Dicho comité debía presentar en el siguiente Congreso Pana- 
mericano a realizarse en Argentina (1983) la versión definitiva de los estatutos.

El contenido temático de ese Congreso puede -hoy por hoy, y a 40 años de distancia- ocupar el contenido de cualquier curso de actualización profesional en Medicina Crítica. Entre los profesores invitados, vale la pena mencionar a los doctores J.M. Civetta, C. Rubianes, S. Burstein, Louis del Guercio, Max Harry Weill, Peter Safar, S.J. Dudrick, W. Shoemaker, J.S. Forrester y Ake Grenvik, entre otros, que por obviedad de tiempo, pero no por ser menos importantes, no voy a mencionar.

En el anuario del Congreso Panamericano e lbérico Excepta Medica, se detallan con elegancia los resúmenes de las conferencias, los simposios, y los trabajos científicos de la época, tanto de los médicos como de las enfermeras.

La importancia de los temas y los nombres de los profesores invitados, tanto nacionales como extranje- ros, dieron el realce y la importancia a este congreso, fortaleciendo nexos en pro de una Medicina Crítica de vanguardia.

Yo, simplemente, lo que quiero resaltar es que los médicos y las enfermeras que fundaron nuestras asociaciones fueron, sin duda, no sólo pioneros, sino los mejores médicos y enfermeras de la época, con una visión que perdurará por siempre. Corresponde ahora a los mejores médicos y a las mejores enfermeras de la época actual no sólo darle continuidad a nuestra disciplina, sino proyectar la mejora de la especialidad más bella que he conocido.

\section{Alfredo F Sierra Unzueta \\ Hospital Ángeles Lomas GASS.}

Correspondencia: E-mail: alfredomedint@gmail.com 